\title{
Investigation of Burnout Levels of Anaesthesiologists and Technicians in Covid-19 Pandemic Period
}

\author{
Gulsum Kavalci', [MD] \\ ORCID: 0000-0002-8245-4721
}

Selvi Ceran Kayipmaz², [MD]

ORCID: 0000-0002-7984-2440

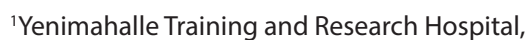
Anesthesia and Reanimation Department, Ankara/ Turkey.

${ }^{2}$ Baskent University Faculty of Medicine, Psychiatry Department, Ankara/Turkey.

Corresponding Author: Gulsum Kavalci Yenimahalle Training and Research Hospital, Anesthesia and Reanimation Department, Ankara/Turkey.

E-mail:gkavalci@yahoo.com

https://doi.org/10.32552/2021.ActaMedica.578

\section{nee) ABSTRACT Con}

Objective: The ongoing Covid-19 pandemic further increased this stress of employees. This disease, which did not have a cure and a vaccine at the beginning, increased the anxiety of the employees and forced them to live separately due to the risk of infecting family members. This study aimed to investigate the burnout levels of doctors and technicians working in Yenimahalle Training and Research Hospital Anaesthesiology and Reanimation Clinic.

Materials and Methods: This study was conducted prospectively by using a questionnaire method in the Yenimahalle Training and Research Hospital. Maslach Burnout questionnaire applied to the participants. Quantitative data were expressed as \%, the number of subjects as (n). The distribution of continuous variables was evaluated with the Kolmogorov-Smirnow test. Qualitative data were expressed in mean \pm SD (standard deviation). $\mathrm{X}^{2}$ test was used for comparison of categorical variables. Independent Student T-test was used for comparison of continuous variables. The relationship between burnout level and variables was determined by Pearson Correlation Test. The value of $\mathrm{p}<0.05$ was considered statistically significant.

Results: A total of 52 volunteers participated in the study. The average emotional exhaustion score of the volunteers participating in the study was $31.13 \pm 4.6$, the average depersonalization score was $15.06 \pm 3.3$, and the mean personal achievement score was $23.60 \pm 3.7$. There was no statistically significant relationship between any of the variables and the burnout level ( $p>0.05)$.

Conclusion: The high level of burnout in a clinic that is at the forefront of the fight against Covid-19, such as anesthesiology and reanimation, is important in terms of determining the situation.

Keywords: Anesthesia, burnout, Covid-19

\section{INTRODUCTION}

Burnout is a feeling of emotional exhaustion, depersonalization, and a decrease in personal accomplishment that often occurs in people, who work face to face with other people as part of their job [1-4]. Those working in the operating room and intensive care unit are constantly under stress due to reasons such as the criticality of the conditions of the patients served, working in shifts, working on weekends and holidays, and working in a closed environment [4]. The ongoing Covid-19 pandemic further increased this stress of employees [511]. This disease, which did not have a cure and a vaccine at the beginning, increased the anxiety of the employees and forced them to live separately due to the risk of infecting family members $[1,7,8]$.

This study aimed to investigate the burnout levels of doctors, technicians, and technicians working in Yenimahalle Training and Research Hospital Anaesthesiology and Reanimation Clinic. 


\section{MATERIALS and METHODS}

This study was conducted prospectively by using a questionnaire method. Ethics committee approval was obtained before the study ( Ankara City Hospital, E1/917/2020). At the time of the study, the hospital was determined as a pandemic hospital. Elective surgery and polyclinic services were stopped. Employees started to work every 4-5 days.

\section{Participants}

A total of 52 people comprising of anaesthesiologists and anesthesia technicians, who volunteered for the study, were included in the study. The criteria for volunteers to be included in the research are: Working at Yenimahalle Training and Research Hospital,Being anaesthesiologist, technicist, or technician, To agree to participate in the study. Exclusion criteria for the volunteers are: Refusing to participate in the study.

\section{Maslach Burnout Inventory}

Human Services Survey for Health Personnel (MBIHSS) [12] was used to assess the burnout among the nurses. It consisted of 22 items, under three different dimensions viz emotional exhaustion, depersonalization, and personal accomplishments. The emotional exhaustion domain assessed by a 9-item scale identifies the feeling of being emotionally overextended and over-exhausted by one's work. Depersonalization domain (5 items) in the tool measures an unfeeling and impersonal response toward the recipient of one's service, care, treatment, or instruction. There are eight items in the personal accomplishment domain, which assesses the feelings of competence and achievements in one's work with people. The subjects were asked to respond to a 6-point Likert scale for measuring each item freely. Based on the obtained score, burnout in different dimensions was categorized as follows (Table 1). The higher the score for emotional exhaustion and depersonalization, the severe is the burnout, while a lower score of personal accomplishment indicates more severe burnout.

\section{Statistical Analyses}

Statistical analyses were made with SPSS 23 for Windows program. Quantitative data were expressed as \%, the number of subjects as (n). The distribution of continuous variables was evaluated with the Kolmogorov-Smirnow test. Qualitative data were expressed in mean $\pm S D$ (standard deviation). $\mathrm{X}^{2}$ test was used for comparison of categorical variables. Independent Student T-test was used for comparison of continuous variables. The relationship between burnout level and variables was determined by Spearman Correlation Test. The value of $p<0.05$ was considered statistically significant.

\section{RESULTS}

\section{Sociodemographic Characteristics of Participants}

A total of 52 volunteers participated in the study. Six (11.5) of the participants in the study were men and 46 (88.5) of them were women. The ages of the participants in the study were between 21 and 50 , the mean age was $37.13 \pm 8.2$. Seven (13.5\%) of the participants in the study were high school graduates and $45(86.5 \%)$ of them were university graduates. The mean working time was $13.96 \pm 8.7$ years. The average wage was $4827.13 \pm 1616.9$ TRY. The sociodemographic data of the volunteers participating in the study are summarized in the Table 2.

\section{Burnout Dimension}

The average emotional exhaustion score of the volunteers participating in the study was $31.13 \pm 4.6$, the average depersonalization score was $15.06 \pm 3.3$, and the mean personal achievement score was $23.60 \pm 3.7$. The burnout characteristics of the volunteers are summarized in the Table 3 . It is seen that employees have high levels of emotional exhaustion, depersonalization, and personal failure.

No statistically significant correlation was found between burnout level and gender, marital status,

Table 1. MBI-human services surveyscore classification

\begin{tabular}{|c|c|c|c|}
\hline & Low burnout & Moderate burnout & High burnout \\
\hline Emotional exhaustion & $0-16$ & $17-26$ & $>27$ \\
\hline Depersonalization & $0-6$ & $7-12$ & $>13$ \\
\hline Personal accomplishment & $>39$ & $32-38$ & $0-31$ \\
\hline
\end{tabular}


Table 2. Sociodemographic characteristics of the participant

\begin{tabular}{|l|c|}
\hline Variable & N (\%), mean \pm SD \\
\hline Age & $37.13 \pm 8.2$ \\
\hline Gender (Male/Female) & $6 / 46$ \\
\hline Education & \\
$\quad$ High school & $7(13.5)$ \\
$\quad$ University & $45^{\prime} \mathrm{i}(86.5)$ \\
\hline Job & \\
$\quad$ Doctor & $10(19.2)$ \\
$\quad$ Technician & $42(80.2)$ \\
\hline Mariatal status & \\
$\quad$ Maried & $41(78.8)$ \\
Single & $11(21.2)$ \\
Child & \\
$\quad$ Yes & $12(23.1)$ \\
$\quad$ No & $40(76.9)$ \\
Hobby & \\
$\quad$ Yes & $37(71.2)$ \\
No & $15(28: 8)$ \\
\hline Study time & $13.96 \pm 8.6$ \\
Cost (TI) & $4827.12 \pm 1616.9$ \\
\hline
\end{tabular}

educational status, profession, presence of children, presence of hobby $(p>0.05)$ (Table 4).

Pearson Correlation Test was conducted to determine the relationship between burnout level and variables (age, gender, salary, working time, hierarchical position, number of children). There was no statistically significant relationship between any of the variables and the burnout level ( $p>0.05$ ).

\section{DISCUSSION}

It was found that the levels of burnout of the healthcare professionals in the clinic were high in this study conducted in an anesthesiology and reanimation clinic, which is at the forefront of the COVID-19 process. Additionally, it was observed that there was no statistical relationship between the burnout level and the participants' gender, marital status, educational status, parental status, occupation, and hobbies. The results of the study reveal the exhaustion, depersonalization, and personal accomplishment of the healthcare professionals during the COVID-19 process in the clinic, where the study was conducted.

At the end of a study conducted in Libya during the pandemic process, it was emphasized that
Table 3. Burnout among participant during COVID-19 pandemic $(n=52)$

\begin{tabular}{|l|c|}
\hline Burnout dimension & Mean \pm SD, $\mathrm{n}(\%)$ \\
\hline Emotional exhaustion & $31.13 \pm 4.5$ \\
Low (0-16) & 0 \\
Moderate (17-26) & $9(17.3)$ \\
High (27-54) & $43(82.7)$ \\
Depersonalization & $15.06 \pm 3.3$ \\
Low (0-6) & 0 \\
Moderate (7-12) & $12(23.1)$ \\
High (13-30) & $40(76.9)$ \\
Reduced personal accomplishment & $23.60 \pm 3.7$ \\
Low >39 & 0 \\
Moderate (32-38) & 0 \\
High (0-31) & $52(\% 100)$ \\
\hline
\end{tabular}

precautions should be taken to increase the welfare of healthcare workers, as the prevalence of mental disorders and insufficient health capacity can lead to suicide, loss, and malpractice in healthcare workers. Because the study found that fear of COVID-19 is associated with high emotional fatigue and depersonalization [7]. In our study, the personal accomplishment levels of the participants were also found to be low. We think that uncertainties in Covid-19 treatment create anxiety in participants and reduce personal accomplishment rates.

In another study investigating burnout and wellbeing among emergency physicians before the pandemic in Canada, it was found that $86.1 \%$ of the participants met at least 1 criterion in terms of burnout. It was also found that $5.9 \%$ had thought of suicide in the previous year [13]. In our study, it was observed that burnout criteria were observed in all of the participants. Emergency medicine, anaesthesiology, and reanimation are disadvantageous in terms of burnout since they are high-risk branches before the pandemic. However, it is obvious that these healthcare workers, who work at the forefront of the pandemic, will be affected more negatively by the pandemic. We think that the uncertainties regarding the treatment and vaccination that existed at the time of the study were effective in the high burnout of our participants.

In our study, personal accomplishment scores were found to be low in all the participants (100\%). The emotional exhaustion and depersonalization scores of the participants, respectively $82.7 \%$ and $76.9 \%$, were also found to be high. In another 
Table 4. Burnout scores according to groups

\begin{tabular}{|c|c|c|c|}
\hline \multirow{2}{*}{\begin{tabular}{|l|} 
Burnout dimensions \\
Gender \\
\end{tabular}} & \multicolumn{2}{|c|}{ Variable } & \multirow[b]{2}{*}{$\mathbf{p}$} \\
\hline & Male (6) & Female (46) & \\
\hline Emotianal exhaustion & $31.67 \pm 4.5$ & $31.07 \pm 4.6$ & NS \\
\hline Depersonalization & $13.67 \pm 3.0$ & $15.24 \pm 3.4$ & NS \\
\hline Reduced personal accomplishment & $24.67 \pm 2.9$ & $23.46 \pm 3.9$ & NS \\
\hline Mariatal status & Maried (41) & Single (11) & \\
\hline Emotianal exhaustion & $31.46 \pm 4.4$ & $29.91 \pm 5.1$ & NS \\
\hline Depersonalization & $14.93 \pm 3.1$ & $15.55 \pm 4.2$ & NS \\
\hline Reduced personal accomplishment & $23.46 \pm 3.6$ & $24.09 \pm 4.5$ & NS \\
\hline Job & Doctor (10) & Technician (42) & \\
\hline Emotianal exhaustion & $32.30 \pm 4.1$ & $30.86 \pm 4.6$ & NS \\
\hline Depersonalization & $15.40 \pm 3.1$ & $14.98 \pm 3.4$ & NS \\
\hline Reduced personal accomplishment & $23.60 \pm 3.6$ & $23.60 \pm 3.8$ & NS \\
\hline Education & High school (7) & Univercity (45) & \\
\hline Emotianal exhaustion & $28.14 \pm 5.6$ & $31.55 \pm 4.3$ & NS \\
\hline Depersonalization & $14.57 \pm 4.3$ & $15.11 \pm 3.3$ & NS \\
\hline Reduced personal accomplishment & $25.86 \pm 4.7$ & $23.18 \pm 3.6$ & NS \\
\hline Child & Yes (40) & No (12) & \\
\hline Emotianal exhaustion & $31.13 \pm 4.7$ & $31.17 \pm 4.5$ & NS \\
\hline Depersonalization & $14.95 \pm 3.2$ & $15.58 \pm 3.9$ & NS \\
\hline Reduced personal accomplishment & $23.54 \pm 3.5$ & $24.25 \pm 4.4$ & NS \\
\hline Hobby & Yes (37) & No (15) & \\
\hline Emotianal exhaustion & $30.97 \pm 4.5$ & $31.53 \pm 4.8$ & NS \\
\hline Depersonalization & $15.32 \pm 3.5$ & $14.40 \pm 3.0$ & NS \\
\hline Reduced personal accomplishment & $23.35 \pm 3.9$ & $24.20 \pm 3.4$ & NS \\
\hline
\end{tabular}

NS: Nonsignificantly

study conducted in Saudi Arabia, these rates were found to be $38.5 \%$ for EE, $31.2 \%$ for DP, and $33.6 \%$ for PA. The rate of burnout levels in our study is significantly higher than this study. In the Saudi Arabian study, shift work patterns, on-call shifts at home, change in working hours, and taking part in the management of COVID-19 patients were associated with higher burnout scores [14]. The high rates in our study compared to this study may be related to the monthly income, working hours, and working conditions of the staff.

It is stated that burnout caused by COVID-19 in healthcare workers can be prevented with early diagnosis and effective intervention [15]. Determining institutional and national policies will be useful in this understanding. Social support, effective communication with the administration, active participation of healthcare professionals in decision-making processes are among the measures that can be taken.

In our study, no statistically significant relationship was found between occupation and education level and burnout level. The fact that the operating room and intensive care units are a closed environment and the employees are always together and they share a lot with each other can be effective in these results. It is also emphasized that one of the important methods of coping with burnout in conditions such as the COVID-19 pandemic is the quality relationships between subordinates and superiors [16]. Teamwork stands out in conditions where blood pressure is high in the working environment such as emergency service, intensive care, and operating room. Hereby, the leadership of the most senior person in the team will contribute to increasing motivation and reducing work-related burnout.

It was determined in another study conducted in Jordan that the main factors leading to burnout are job stress, lack of personnel-resources, fear of infection, and relationships between professions [5]. In our study, the depersonalization and emotional exhaustion rates were high and the personal accomplishment rate was low. The fact 
that the problems experienced by healthcare workers in the pandemic and the resulting burnout are common in many different regions of the world from the Middle East to North America draws attention when looking at the publications in the literature.

In our study, no significant correlation was found between burnout and age, gender, salary, working time, and the number of children.

\section{Limitations of This Study}

The main limitation of our study is that it is single centered. Another limitation is that the relationship between covid-19 passing and the level of burnout has not been investigated.

\section{CONCLUSION}

The high level of burnout in a clinic that is at the forefront of the fight against COVID-19, such as anesthesiology and reanimation, is important in terms of determining the situation. Once the problem has been identified, it will be easier to take steps towards a solution. Thanks to the steps to be taken early, burnout, depersonalization, and personal failure might be prevented.

\section{CONFLICT Of INTEREST STATEMENT}

Author's decelerated that no conflict of interesting.
[1] Jose S, Dhandapani M, Cyriac MC. Burnout and Resilience among Frontline Nurses during COVID-19 Pandemic: A Cross-sectional Study in the Emergency Department of a Tertiary Care Center, North India. Indian Journal of Critical Care Medicine 2020;24(11)1081-8.

[2] Salvagioni DAJ, Melanda FN, Mesas AE, et al. Physical, psychological and occupational consequences of job burnout: a systematic review of prospective studies. PLOS ONE 2017;12(10):e0185781. DOI: 10.1371/journal. pone.0185781.

[3] Ersoy S, Kavalci C, Yel C, et al. Tıp Fakültesi Hastaneleri ve Sağlık Bakanlığı Eğitim ve Araştırma Hastanelerinde Çalışan Acil Tıp Asistanlarının Tükenmişlik düzeylerinin karşılaştırılması. Ankara Med J 2014;14(2):41-5

[4] Turgut N, Karacalar S,Polat C, et al. Uzmanlık eğitimi alan doktorlarda Tükenmişlik sendromu. Turk J Anaesthesiol Reanim 2016;44:258-64.

[5] Algunmeeyn A, El-Dahiyat F, Altakhineh MM, et al. Understanding the factors influencing healthcare providers' burnout during the outbreak of COVID-19 in Jordanian hospitals. Journal of Pharmaceutical Policy and Practice 2020;13:53. https://doi.org/10.1186/s40545-02000262-y

[6] Ozgunay SE, Akca F, Karasu D, et al. Coronavirüs (COVID-19) Pandemi Sürecinde, Anestezistlerin Yaşadıkları Korku Düzeyleri ve Profilaksi Uygulamalarının Değerlendirilmesi. JARSS 2021;29(1):25-31 doi: 10.5222/jarss.2021.40412

[7] Elhadi M, Msherghi A, Elgzair M, et al. Burnout Syndrome Among Hospital Healthcare Workers During the COVID-19 Pandemic and Civil War: A Cross-Sectional Study. Frontiers in Psychiatry 2020;11: 579563 doi: 10.3389/ fpsyt.2020.579563

[8] Chaput B, Bertheul N, Jacques J, et al. Professional Burnout Among Plastic Surgery Resident. Annals of Plastic Surgery 2015;75:2-8. Doi: 10.1097/SAP.0000000000000530
[9] US Department of Veterans Affairs. Managing healthcare workers' stress associated with the COVID-19 virus outbreak. PTSD: National Center for PTSD. 2020. Available at: https://www.ptsd.va.gov/covid/ COVID_healthcare_ workers.asp. Accessed April 4, 2020

[10] Khosravi M. Burnout in hospital medical staff during the COVID-19 pandemic: diagnosis, treatment, and prevention. Sapporo Medical Journal 2020;54:8.

[11] Shreffler J, Petrey J, Huecker M, The Impact of COVID-19 on Healthcare Worker Wellness: A Scoping Review. Western Journal of Emergency Medicine. 2020;21(5):1059-66

[12] Maslach C, Jackson SE. The measurement of experienced burnout. J Occupat Behav 1981;2(2):99-113. Available from https://onlinelibrary. wiley.com/doi/abs/10.1002/ job.4030020205

[13] Lim R, Van Aarsen K, Gray S, et al. Emergency medicine physician burnout and wellness in Canada before COVID19: A national survey. CJEM 2020;22(5):603-607. https://doi.org/10.1017/cem.2020.431

[14] Alanazi KH, bin Saleh GM, AlEidi SM, et al. Prevalence and Risk Factors of Burnout among Healthcare Professionals during COVID-19 Pandemic - Saudi Arabia. American Journal of Public Health Research 2021;9(1): 18-27. doi:10.12691/ajphr-9-1-3

[15] Kisa S. Burnout among Physicians and Nurses during COVID-19 Pandemic. European Journal of Environment and Public Health 2020;4(2): em0055

[16] De Moura EC, Furtado L, Sobral F. The Burnout epidemic during the covid-19 pandemic: the role of Imx in alleviating physicians' burnout. RAE 2020;60(60):426-436. DOI:http:// dx.doi.org/10.1590/S0034-759020200606 